\title{
Legado e rupturas da Revolução Soviética desde as lutas sociais na América Latina
}

Lia Pinheiro Barbosa

Resumo: É inegável o legado da Revolução Soviética de 1917 para o crisol da resistência histórica latino-americana e caribenha, sobretudo nas revoluções desencadeadas a partir de meados do século XX. O presente escrito apresenta alguns elementos de releitura teórica e históricopolítica da Revolução Soviética nas lutas sociais de fim de século, em particular aquelas articuladas pelos movimentos sociais, no caso, o Movimento Zapatista.

Palavras-chaves: Revolução Soviética. América Latina. Zapatistas.

\section{Legacy and ruptures of the Soviet
Revolution from the social struggles in
Latin America \\ Legacy and ruptures of the Soviet
Revolution from the social struggles in
Latin America \\ Legacy and ruptures of the Soviet
Revolution from the social struggles in
Latin America}

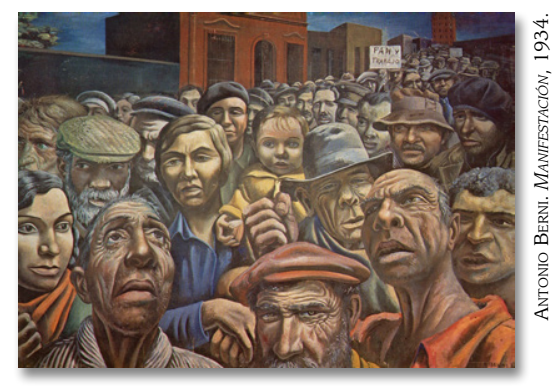

Abstract: The legacy of the 1917 Russian Revolution for the melting pot of Latin American and Caribbean historical resistance is undeniable, especially with regard to the revolutions that began in the mid-twentieth century. The present paper offers some elements for a theoretical and historical-political re-reading of the Russian Soviet Revolution through the lens of the social struggles of the end of the century, in particular those articulated by social movements, in this case, the Zapatista Movement of Mexico.

Keywords: Russian Revolution. Latin America. Zapatistas.

Conselho Latino-Americano de

Ciências Sociais (CLACSO). Membro

da International Gramsci Society-

Brasil. E-mail: lia.barbosa@uece.br.

RECEBIDO 11.05.2017 


\section{A MODO DE INTRODUÇÃO: O SÉCULO XX E AS REVOLUÇÕES NA AMÉRICA LATINA E NO CARIBE}

A Revolução Soviética de 1917 ultrapassou as fronteiras nacionais, tornando-se um ícone e uma inspiração para os processos de resistência política que se sucederam ao longo do século XX, em âmbito internacional. Entre aqueles que receberam significativa influência soviética em processos políticos internos, encontramos a América Latina e o Caribe, sobretudo em meados do século XX, período de efervescência das revoluções nesse continente.

Para situarmos o contexto das revoluções latino-americanas e caribenhas, é fundamental que reconheçamos, como ponto de partida, especificidades do processo histórico de nossa formação sociocultural, política e econômica, as quais nos darão nome como continente e uma identidade regional/nacional. Tal processo tem suas raízes nas colonizações, na consolidação do latifúndio e na do sistema escravocrata como matriz produtiva e política, uma tríade que exerceu influência na natureza dos Estados nacionais, nas relações sociais, nas diferentes fases das forças produtivas e das relações de produção correntes na região, até culminar no atual estágio de desenvolvimento do capitalismo de cunho transnacional e dependente (BAMBIRRA, 1980; MARINI, 2000; GONZÁLEZCASANOVA, 2015). Essa tríplice natureza engendrou uma profunda segregação social e um antagonismo de classe determinados, por um lado, pela condição estrutural de quem (não) detém os meios de produção e, por outro, pelo lugar social atribuído pelos conquistadores (e pelas elites nacionais pós-colonização) aos povos indígenas, aos afrodescendentes e aos camponeses (que, na maioria dos países do continente, descendem dos dois primeiros).

Entretanto, como é próprio do movimento dialético da história social, as raízes da subalternização dos povos na América Latina e no Caribe demarcaram a natureza das resistências que se constituíram no campo e na cidade. Não é nosso propósito aternos a uma apresentação minuciosa da genealogia das rebeliões, das lutas populares, das diferentes resistências que se erigiram durante a "longa noite dos 500 anos", $^{1}$ até porque dispomos de

1 Metáfora usada pelos zapatistas na Primeira Declaração da Selva Lacandona, em alusão ao que representou a conquista da América Latina. 
registros historiográficos, sociológicos, antropológicos e políticos que deram (e dão) conta de analisar, amiúde, suas especificidades nacionais e regionais em diferentes períodos de nossa história.

A nossa intenção é realizar uma aproximação reflexiva em diálogo com a Revolução Soviética de 1917, com o intuito de apontar nossas especificidades regionais e quais respostas políticas as lutas latino-americanas e caribenhas deram às problemáticas de um período histórico comum, muito embora com matizes diferenciados. Dessa maneira, entre as primeiras expressões das lutas articuladas no início do século em referência, estão aquelas que propunham uma revolução como ponto de partida na construção de um projeto nacional-popular emancipatório.

A Revolução Mexicana de 1910 inaugurou as grandes revoluções de caráter popular da América Latina no século XX. Baseada nos princípios teórico-políticos do anarcossindicalismo e do agrarismo, se tratou de uma revolução articulada por forças populares camponesas e indígenas contra a ditadura de Porfírio Díaz (HERZOG, 1972; WARMAN, 1976; KATZ, 1998; GILLY, 2007). Logo, emergiram aquelas lideradas por movimentos de libertação nacional, clandestinos e de guerrilha armada, que culminaram em movimentos revolucionários, a exemplo da Revolução Cubana, em 1959 (BELL et. al., 2006) e da Revolução Sandinista na Nicarágua, em 1979 (MARTÍ I PUIG, 2012).

As consignas políticas de tais revoluções recuperavam a denúncia histórica da função sociocultural e política do latifúndio no processo de expropriação territorial e na paulatina subalternização dos povos indígenas e camponeses. No caso da Revolução Mexicana, o lema "Terra e Liberdade" e a consigna "a terra é de quem nela trabalha", ambos imortalizados por Emiliano Zapata e Pancho Villa, traduziam a reivindicação da posse da terra e a realização da reforma agrária como base de um projeto nacional -popular para o México. Para o caso cubano e nicaraguense, inspirados pela Revolução Soviética de 1917, a perspectiva da luta de classe e a urgência por construir o projeto socialista constituíam o horizonte político para a emancipação humana. 
Vale destacarmos que, na primeira metade do século XX, Augusto César Sandino liderou a primeira insurgência revolucionária na Nicarágua, cujo lema político - "Pátria e Liberdade" herdava grande influência da Revolução Mexicana de 1910. Aliás, Sandino esteve no México entre 1923 e 1926, momento em que se aproximou do debate teórico-político do anarcossindicalismo e do agrarismo mexicano, particularmente das reflexões e escritos políticos de Ricardo Flores Magón.

Naquele período, o mundo já havia vivenciado o contexto da $1^{a}$ Guerra Mundial e se acirrava o campo de disputa político-ideológica entre o capitalismo e o socialismo, não só na Europa, mas também nas Américas. Para Sandino, o contexto de guerra apresentava uma contradição de origem na proposição de um projeto político emancipatório, no sentido de que, por ser uma guerra de capitais, o patriotismo que se defendia se restringia a uma perspectiva burguesa, reflexão que era comum ao anarcossindicalismo. Nessa linha, influenciado pela posição política ácrata e libertária socialista, Sandino reformulou o conceito de pátria em uma perspectiva revolucionária. No seu argumento, considerava inconcebível a defesa da pátria ou do patriotismo dissociado da liberdade e de sua concessão, na sua mais ampla dimensão, à classe trabalhadora. Portanto, argumentava que as classes subalternas deveriam ser as primeiras em defender a pátria contra a expropriação estrangeira que, no caso particular da Nicarágua, representava a guerra contra os Estados Unidos. O movimento liderado por Sandino foi precursor dos movimentos de libertação nacional da metade do século XX. ${ }^{2}$

Um elemento comum dessas revoluções - no México, na Nicarágua e em Cuba - era o anseio por construir um projeto emancipatório de base popular e articulado por sujeitos histórico-políticos do campo e da cidade. Entretanto, elas guardam suas diferenças e especificidades com relação à concepção teórica do processo revolucionário, bem como no tocante às estratégias internas da luta. Para o caso mexicano, a bandeira revolucionária estava

2 Para um aprofundamento da revolução na Nicarágua, consultar Bedaña (2016). 
alicerçada pelos princípios do anarcossindicalismo e do agrarismo, muito embora também se nutrisse da memória histórica das lutas passadas, de rebeliões indígenas de caráter libertador. No sul do país, por exemplo, se deram rebeliões históricas que almejaram como horizonte político uma ruptura com a herança colonial, que impunha suas marcas nas relações espaciais, socioculturais e políticas, especialmente no trato conferido às populações indígenas. ${ }^{3}$

Nos casos de Cuba e da Nicarágua, inspiravam-se diretamente na Revolução Soviética de 1917 e no debate teórico-político do marxismo-leninismo. ${ }^{4}$ Entretanto, com a ascensão de Stalin ao poder, houve um reordenamento do socialismo soviético, ao assumir como estratégia política a "revolução por etapas". Tal estratégia propunha estabelecer uma aliança de luta e de poder político com a burguesia, transpondo a revolução socialista de caráter popular para um momento posterior. Nessa direção, o Partido Comunista da URSS determinou que os demais partidos comunistas devessem seguir a deliberação política soviética.

A deliberação do Partido Comunista da URSS resultou em dissidências nos demais países. A primeira ruptura com o socialismo soviético ocorreu com a Revolução Chinesa de 1949, maiormente com o fundamento da centralidade proletária de Lênin e Trotsky, ambos defensores do proletariado como sujeito revolucionário. Para Mao Tsé-Tung, o campesinato era o sujeito revolucionário por excelência e a estratégia revolucionária para o socialismo deveria ser o partido-exército. Conforme Mao Tsé-Tung (2008), o chamado "bloco das quatro classes" - burguesia nacional, pequena burguesia urbana, proletariado e exército camponês - conformaria

3 A historiografia e a antropologia mexicanas dão conta de apresentar-nos as resistências indígenas internas do país. Entretanto, no campo literário, encontramos um detalhamento maior da natureza colonial das relações sociais, particularmente nas obras da escritora Rosário Castellanos (2007; 2012), que nos apresenta fidedignamente as múltiplas expressões da violência contra os indígenas, seja no âmbito doméstico (a exploração sexual e laboral das mulheres indígenas), como no terreno político-econômico.

4 No século XX, também ganham destaque as guerrilhas clandestinas, a propósito do Sendero Luminoso, no Peru, e das Forças Revolucionárias Armadas da Colômbia (FARC), ambas criadas na década de 1960. Não é o nosso propósito adentrar na análise dos elementos políticos que as articulam. 
a força política responsável por conduzir o processo revolucionário, por meio da estratégia da guerra popular prolongada.

Similarmente houve rupturas com o socialismo soviético em Cuba e na Nicarágua. O Movimento 26 de Julho, liderado pelos revolucionários Fidel Castro e Ernesto Che Guevara, se tornou dissidente do Partido Comunista Cubano, convertendo-se em um movimento insurgente de guerrilha armada que se contrapôs às deliberações de Stalin e do Partido Comunista da URSS. No caso da Revolução Sandinista, abriram-se três frentes divisionistas: 1) a da guerra popular prolongada, baseada no maoísmo e no foco de guerrilha guevarista; 2) a de aliança entre os proletários urbanos das fábricas e os proletários rurais das plantações, de linha soviética; e 3) a dos insurreicionistas ou terceiristas, conformada por setores da burguesia, que defendiam ações espetaculares, como, por exemplo, explosões, porém esvaziadas de uma análise política crítica. Esta última frente se tornou, posteriormente, socialdemocrata (BLACK, 1981).

O ciclo de revoluções da América Latina e do Caribe desencadeou processos políticos de grande envergadura, tanto no âmbito interno de cada país, bem como em perspectiva regional. Do ponto de vista de uma reforma intelectual e moral (GRAMSCI, 1981), paulatinamente se concretizou o ideário de Simón Bolívar e de José Martí, no sentido de consolidar uma práxis política e um pensamento social latino-americano e caribenho, de caráter revolucionário, polinizado por referentes das lutas históricas travadas nos contextos nacionais, mas igualmente inspirados por aquelas de caráter internacional. No seio revolucionário latino-americano, uma gleba da resistência popular germinava em território regional, afirmando como sujeitos revolucionários os povos indígenas, os camponeses ${ }^{5}$ e a classe trabalhadora do campo e da cidade.

5 Outros processos políticos são de grande importância para compreender as lutas sociais latino-americanas do século XX, especialmente aqueles relacionados à resistência indígena e camponesa. Para conhecimento, sugerimos a compilação coordenada por Pablo González Casanova, que reúne uma coletânea de 04 volumes que abarca a totalidade da região. Cf. GonzálezCasanova (1984; 1985a; 1985b; 1985c). 
Não obstante, nas décadas seguintes, a disputa hegemônica no plano internacional intensificou o combate a todo e qualquer ideário do comunismo e do socialismo no continente, a exemplo das ditaduras militares no Cone Sul, impulsadas ao longo da Guerra Fria. O advento das ditaduras militares e o fortalecimento da ideologia da Guerra Fria impediram uma expansão das lutas revolucionárias na região. E, mesmo durante a transição democrática, prevaleceu um arranjo político que manteve no poder as forças políticas vinculadas às oligarquias agrárias e ao capital financeiro internacional.

Entretanto, uma vez mais, o movimento dialético da história e a contradição própria do capitalismo desencadearam um novo ciclo da luta de classes ao final do século XX. Nesse horizonte, o ideário revolucionário se reavivava na América Latina e a transição de séculos aponta a um câmbio epocal, marcado pela emergência de lutas emblemáticas no campo latino-americano, conduzidas pelos movimentos sociais indígenas e camponeses, os quais se reposicionaram no processo histórico da resistência revolucionária e radicalizaram as vias para a consolidação de um projeto nacional-popular.

Em perspectiva histórica, abre-se, nos umbrais do século XXI, um novo período para a disputa hegemônica na América Latina, que certamente herda elementos de ordem político-ideológica e teórica das lutas revolucionárias contemporâneas, entre elas a Revolução Soviética de 1917.

\section{O SUJEITO HISTÓRICO INDÍGENA E CAMPONÊS COMO SUJEITO DA REVOLUÇÃO}

Embora a centralidade do proletariado urbano constituísse um dos pilares do socialismo soviético, o impacto do capitalismo no campo era central no debate da Rússia pré-revolucionária, uma vez que já se identificava o desenvolvimento das forças produtivas no campo. Deparar-se com a expansão do capitalismo no campo representava um desafio para o socialismo, sobretudo para aqueles que reconheciam no campesinato o sujeito revolucionário: como traçar os caminhos, do ponto de vista revolucionário, 
para a superação da servidão e da subalternidade ao capital em seus territórios?

Apropriando-se do materialismo histórico-dialético como método analítico, José Carlos Mariátegui inaugurou um marxismo latino-americano e inovou vitalmente o debate político do período, ao sustentar que o sujeito revolucionário na América Latina era representado pelos povos indígenas, em virtude da especificidade de nossa formação histórica e política (MARIÁTEGUI, 1928), tese refutada pela Internacional Comunista, que afirmava cabalmente que o sujeito revolucionário encontrava-se nas fábricas, ou seja, o proletariado industrial. Muito embora na Rússia pré-revolucionária houvesse a percepção do campo como espaço de disputa do capital, sob a ótica do marxismo ortodoxo europeu, o campesinato era invisibilizado, subestimado e excluído como sujeito partícipe do processo revolucionário. E os povos indígenas sequer eram mencionados!

Mariátegui (1928) argumentava que todas as teses que ignoravam a problemática indígena ou a reduziam abstratamente a um problema étnico e moral se limitavam a "exercícios teóricos estéreis", portanto, "condenados a um descrédito absoluto". Com base nessa premissa, Mariátegui (1928) estabeleceu uma ruptura epistemológica e política fundamental para inaugurar uma abordagem marxista e socialista em perspectiva latino-americana, sobretudo quando situou a questão indígena como um "problema nacional" e um "conceito a se criar". ${ }^{6}$ Ao analisar o caso peruano, Mariátegui identificou uma herança direta do colonialismo relacionada à problemática da terra: o "gamonalismo",7 o latifúndio e a servidão, pilares de um modelo de desenvolvimento político-econômico que perdurava há séculos no Peru e que era responsável pela miséria moral e material indígena. À luz dessa assertiva,

6 A ruptura epistemológica de Mariátegui também se manifesta na dupla dialética internacionalismo-nacionalismo e urbanismo- agrarismo. De igual maneira, situa no plano teórico-político o que ele definia como "comunismo agrário dos Incas".

7 Mariátegui (1928) utilizava a categoria "gamonalismo" para designar o regime econômico e social sucessor do feudalismo colonial, e que era representado por uma estrutura política que tinha nos gamonales (latifundiários ou grandes proprietários agrícolas) uma das principais forças políticas. 
Mariátegui defendia que o socialismo na América Latina deveria incorporar, no seio do debate político, uma concreção histórica que reconhecesse na propriedade da terra as raízes da questão indígena, demarcando-a, em outros termos, como um problema social, político e econômico. Conforme destaca Zea (2000), no pensamento marxista de Carlos Mariátegui:

Los indígenas deben ser vistos como hombres concretos que son como todo los hombres, con una etnia, una cultura, una concepción del mundo de la que hay que partir para relacionarnos con otras etnias, culturas y concepciones del mundo, tratando de comprender y hacerse comprender, lo cual no es posible si en lugar de incorporar al indígena a la nación, se lo margina en una supuesta y falsa defensa de su identidad. (ZEA, 2000, p. 223).

Mariátegui identificava, ainda, a existência de elementos germinais para pensar um socialismo indoamericano, cuja evidência se expressava na sobrevivência de tradições comunais do campesinato-indígena em contextos de desenvolvimento do capitalismo, o que lhes conferia uma especificidade distinta com relação à natureza da contradição capital-trabalho predominante na Europa. Portanto, se o sujeito subalternizado diferia do ponto de vista de sua raiz histórica, sociocultural e espacial, a via para o socialismo em nossa região igualmente seria diferenciada.

Uma particularidade fundamental do pensamento político de Mariátegui com relação ao legado da Revolução Soviética consiste que, na sua concepção do processo revolucionário, há uma ruptura com a perspectiva "partidocêntrica", orientada à tomada do poder. Mariátegui defendia a premente necessidade de uma articulação entre as reivindicações proletário-urbanas e as indígenas agrárias, o que lhes permitiria uma confluência política entre sujeitos coletivos rumo a um projeto histórico, nacional e socialista edificado desde abaixo, isto é, na base popular. Nessa linha, a realização de um projeto socialista não seria obra de uma elite intelectual ou de um partido político, muito menos de uma bancarrota do capitalismo, seria antes o resultado de um trabalho coletivo de construção histórica. Daí que, para Mariátegui, a educação política permanente e o fomento de processos auto-organizativos 
eram centrais no processo revolucionário socialista. Na perspectiva de um socialismo indoamericano, enfatizava que a superação histórica da problemática indígena deveria ser obra dos próprios indígenas, fruto de sua consciência histórica como sujeito histórico-político. Em suas palavras:

Una conciencia revolucionaria indígena tardará quizás en formarse; pero una vez que el indio haya hecho suya la idea socialista, le servirá con una disciplina, una tenacidad y una fuerza en la que pocos proletarios de otros medios podrán aventajarlo. El realismo de una política revolucionaria, segura y precisa [...] puede y debe convertir el factor de raza en un factor revolucionario. (MARIÁTEGUI, 1982, p. 185 - 186).

Para Mariátegui (1982), a construção de uma teoria marxista em perspectiva latino-americana exigia, como condição imprescindível, levar em consideração o legado cultural e político indigenista, no sentido de efetuar uma síntese teórico-política entre tradição e modernidade. Com base neste argumento, Mariátegui (1982) imputou ao marxismo um processo contínuo de refundação no sentido de que, embora tenha sua natureza internacionalista, deve apropriar-se das especificidades histórico-culturais dos contextos regionais e nacionais. Em outras palavras, a edificação do marxismo latino-americano tem por tarefa adequar uma teoria universal às especificidades históricas e às coordenadas espaciais e temporais intrínsecas à região, que podem ser traduzidas, na luta contemporânea articulada pelos zapatistas, como os "calendários" e as "geografias"8 das lutas sociais.

Recuperar a análise de Mariátegui (1982) nos permite apontar a capacidade criadora de nossas revoluções e a maneira como se apropriaram do legado da Revolução Soviética em diálogo com a memória história da resistência latino-americana e caribenha.

8 Os documentos e comunicados zapatistas se referem aos "calendários" e às "geografias", no sentido de definir uma temporalidade para a luta indígena e um aprofundamento da concepção política clássica, expressa nas coordenadas de uma direita, uma esquerda, um centro ou seus extremos. Para eles, cada luta terá sua própria organização temporal e espacial, o que representa não estar à mercê de uma direção política impositiva, moldada nos parâmetros de referentes alheios às especificidades da luta indígena. 
Nessa direção, o século XX tem dado exemplos concretos da certeira análise de Mariátegui, no sentido do paulatino fortalecimento de um sujeito histórico-político indígena e camponês, que forja sua consciência política na dialética da luta, impulsando processos revolucionários de relevo em nossa região.

O coetâneo movimento histórico da luta latino-americana e caribenha de fim de século recobra, na práxis política dos movimentos sociais indígenas e camponeses da região, o ideário político revolucionário. Nessa direção, tais movimentos recuperam com vigor o acúmulo de uma trajetória política de mais de cinco séculos (e que contém nela o projeto socialista) e alargam o debate teórico, bem como o horizonte político acerca do papel que devem desempenhar, como força histórico-política, na superação do capitalismo. No percurso de consolidação de projetos políticos que se propõem emancipatórios, há a incorporação de estratégias de luta, para além do partido e dos sindicatos, estes reconhecidos pela esquerda latino-americana como espaços legítimos da direção política na tradição da teoria crítica marxista.

Importa destacar que o final do século XX apresentava novos núcleos de tensão (SVAMPA, 2009) ${ }^{9}$ que desafiavam os movimentos sociais a transcender a natureza de suas reinvindicações políticas e os caminhos de construção/consolidação de uma nova hegemonia. A conjuntura política desse período estava atravessada por quatro fatores que interferiram diretamente nas relações de poder internas entre os Estados latino-americanos (OLIVER, 2016): a globalização do capital; a fragmentação social; a crise das instituições políticas e a emergência de novas formas de resistência social, no campo e na cidade.

O aprofundamento das contradições sociais e político-econômicas resultante desse processo interno do capitalismo neoliberal e pós-ditatorial fez eclodir, com expressiva contundência, um novo ciclo de lutas contestatórias e revolucionárias na América

9 Maristela Svampa afirma que os núcleos de tensão são resultado das formas de controle e disciplinamento social; se caracterizam por uma profunda criminalização do protesto social e do avanço da militarização e de uma legislação antiterrorista. 
Latina. A luta de classe permanecia como bússola no enfrentamento político-ideológico do neoliberalismo e da transnacionalização do capital, que se intensificava no campo latino-americano. Entretanto, uma parte significativa dos movimentos sociais incorporaram as matrizes da luta anticolonial no âmbito dos discursos e dos documentos políticos por eles produzidos, a propósito da denúncia histórica das relações coloniais que se erigiram sob a categoria raça e os signos de opressão dela derivada para os povos indígenas e camponeses. A denúncia do latifúndio e do solapamento da racionalidade epistêmica dos povos indígenas, a consolidação da contradição histórica campo-cidade, entre outras opressões, tornaram-se insumos da luta popular no enfrentamento do Estado moderno ocidental capitalista. Reavivou-se, pois, o debate aberto por José Carlos Mariátegui na primeira metade do século XX. ${ }^{10}$

Entre as lutas emblemáticas que se erigiram no cenário latino-americano ao final do século XX, se destacam a insurgência armada do Exército Zapatista de Libertação Nacional (EZLN) e o surgimento do Movimento dos Trabalhadores e Trabalhadoras Rurais Sem Terra (MST). ${ }^{11}$ Ambas recuperaram e articularam ao seu debate teórico e ao projeto político o conjunto dos referentes históricos da luta anticolonial e da luta de classes em perspectiva regional e internacional. O fortalecimento das lutas no campo latino-americano provocou uma retomada da concepção e das estratégias de consolidação de uma luta popular "desde abaixo". ${ }^{12}$

10 Um dos documentos históricos que consideramos fundamentais na denúncia do colonialismo e sua evolução no processo histórico de consolidação das relações de dominação e poder na América Latina é a Primeira Declaração da Selva Lacandona, lida no dia da Insurgência Armada Zapatista de 1994. Neste documento, o Exército Zapatista de Libertação Nacional (EZLN) se assume como "filhos da longa noite dos 500 anos" e nos apresenta a evolução das diferentes expressões da colonização durante os cinco séculos subsequentes a 1942.

11 A Guerra do Gás e a Guerra da Água na Bolívia, bem como a gênese da Via Campesina Internacional e da Coordenadoria Latino-Americana de Organizações do Campo (CLOOC), constituem outras expressões do fortalecimento das lutas indígenas e camponesas no âmbito internacional.

12 Inclusive a própria nomenclatura "desde abaixo" se torna uma categoria política para tais movimentos. 
É a entrada em cena de um sujeito histórico-político e de uma concepção da práxis política que se reconfiguram no campo de disputa hegemônica. Nesse sentido, reordenam teoricamente os fundamentos que dão sentido à concepção de um projeto político socialista, no qual se reivindica outro sujeito histórico-político para sua consolidação, para além dos partidos e dos sindicatos. De igual maneira, se prima por construir uma agenda política que contempla os desafios que inaugura o século XXI para a América Latina, resultantes das próprias contradições herdadas no transcurso de desenvolvimento do capitalismo em nossa região.

Os movimentos sociais indígenas e camponeses são um sujeito político de longa tradição histórica, que fia sua práxis política em um processo contínuo de recuperação da memória longa e curta (CUSICANQUI, 1986) das lutas travadas em outros momentos da histórica resistência latino-americana e caribenha. O reconhecimento da dialética histórica das opressões faz com que identifiquem um processo de subalternização histórica comum na América Latina e no Caribe, isto é, identificam que não se trata de processos isolados em cada país, mas que se obedece a um padrão comum de dominação, cujas raízes encontram nas colonizações a pedra fundamental, fato que lhes atribui uma marca histórica distinta aos processos de subalternização europeia. Portanto, assumem como tarefa histórica a de debater, com profundidade, a contradição estrutural subjacente ao capital e própria dele, incorporando-a a uma agenda política mais ampla das lutas na transição de séculos. A identidade política desses movimentos não se restringe aos elementos constitutivos da esquerda internacional, a propósito dos princípios que fundamentam o comunismo e o socialismo como horizonte político. Sem negar os princípios socialistas, incorporam uma dimensão epistêmica na conformação das subjetividades políticas, atrelada à memória histórico-cultural que os constitui como sujeitos políticos (BARBOSA, 2013; 2015).

Para fins da presente análise, trataremos de recuperar alguns elementos que dão conta de evidenciar o legado e as rupturas da Revolução Soviética na transição de séculos. Para tanto, 
apresentaremos uma releitura a partir da práxis política do Movimento Zapatista, no México. ${ }^{13}$

\section{INSURGÊNCIA ZAPATISTA E A CONSTRUÇÃO DE OUTRO MUNDO POSSÍVEL, ABAIXO E À ESQUERDA}

"Um mundo onde caibam muitos mundos, abaixo e à esquerda, o lugar onde bate o coração": esta é uma das mais reconhecidas consignas políticas do Movimento Zapatista, movimento indígena conhecido internacionalmente pelo levantamento armado realizado no dia 01 de janeiro de 1994, data em que entrou em vigor o Tratado de Livre Comércio das Américas (TLC).

Para a intelectualidade, alguns movimentos sociais, organizações e partidos da esquerda internacional e mexicana, o Zapatismo não contempla os ideários revolucionários do socialismo soviético ou mesmo das demais revoluções correntes no mundo, à luz da Revolução Soviética de 1917. Entretanto, consideramos que é um equívoco tal consideração, uma vez que há interfaces presentes em documentos produzidos pelos próprios zapatistas que apontam ressonâncias da Revolução Soviética como um legado importante e inspirador da insurgência armada e da elaboração teórica zapatista. Conforme o então Subcomandante Insurgente Marcos, ${ }^{14}$ a formação do EZLN incorpora três vertentes centrais: "un grupo político-militar, un grupo de indígenas politizados y muy experimentados, y el movimiento indígena de la Selva" (LE BOT, 1997, p. 52). No primeiro caso, se referia a um grupo político-militar de corte marxista-leninista, composto por mestiços provenientes do espaço urbano, convictos de que a luta pacífica estava esgotada em suas possibilidades políticas. Portanto, defendiam o retorno da via armada como caminho de luta rumo ao socialismo. À luz dessa

13 A opção por apresentar o caso zapatista decorre de três fatores: 1) por ser o único movimento social, ao final do século XX, que recorreu ao levantamento armado como forma de resistência política na América Latina; 2) por ser o movimento que tem sido criticado pela esquerda internacional reiteradas vezes, sobretudo por não aceitar os argumentos apresentados pelo movimento na crítica à tomada do poder como estratégia de luta; e 3) por ser o movimento que melhor expressa as rupturas e as continuidades do socialismo do século XXI. 14 Hoje, Subcomandante Insurgente Galeano. 
convicção estratégica, iniciaram a organização político-militar a partir dos aprendizados das guerrilhas centro-americanas e das Forças de Libertação Nacional, no México (CEDILLO-CEDILLO, 2010; GUNDERSON, 2013; BARBOSA, 2013).

Segundo o Subcomandante Insurgente Marcos, era necessário conformar uma força político-militar que fosse capaz de:

\section{[...] enfrentar, por medio de una guerra popu- lar, al poder, derrotarlo e instaurar un gobierno hacia el socialismo y hacia la implantación de la dictadura del proletariado y del comunismo. $Y$ en ese sentido se planteaba una guerrilla en términos muy cercanos al foco guerrillero. (LE BOT, 1997, p. 52).}

Nessa primeira vertente, o enfoque na implantação da ditadura do proletariado e do comunismo revela a incorporação da teoria crítica marxista como horizonte político-ideológico, ao mesmo tempo em que se identifica a confluência de duas matrizes centrais para a estruturação do EZLN: a inspiração no foco guerrilheiro guevarista e o anseio em conformar um movimento de libertação nacional para uma transição da democracia ao socialismo, próprio da Revolução Sandinista. Por outro lado, assumir a identidade política do Exército Zapatista de Libertação Nacional remete à memória histórico-política da Revolução Mexicana de 1910 e ao líder camponês Emiliano Zapata. ${ }^{15}$ Segundo o Subcomandante Insurgente Marcos, "de la época de la guerra de Independencia, aprendimos del ejército de Morelos, y de la Revolución, sobre todo de la División del Norte, de Villa, y del Ejército Libertador del Sur, de Zapata" (LE BOT, 1997, p. 59).

As outras duas vertentes da origem do EZLN são resultado do encontro entre o grupo político-militar e o tecido social gerado nos anos de gestação do movimento popular em Chiapas, ${ }^{16} \mathrm{em}$ que participaram organizações indígenas de esquerda e da ação político-missionária da Teologia da Libertação, representada pela Diocese de San Cristóbal de las Casas (LEYVA-SOLLANO, 1994).

15 Durante a Revolução Mexicana, Emiliano Zapata estava à frente do Exército Libertador do Sul e Pancho Villa era o responsável pelo Exército Libertador do Norte. 16 Estado mexicano onde houve o levantamento armado. 
Do encontro com estas forças culturais e histórico-políticas, se conforma a estrutura orgânica de mando e hierarquia militar do EZLN, representada pelo Comitê Clandestino Revolucionário Indígena e pela Comandância Geral (CCRI-CG EZLN). Conforma-se um exército revolucionário de indígenas camponeses, com disposição para matar ou morrer em favor do projeto socialista e da emancipação dos povos indígenas do México.

O processo de preparação militar aconteceu na Selva Lacandona, no aprendizado das estratégias de sobrevivência e de mobilidade neste território, além da formação militar para o prelúdio da insurgência armada, com base nos textos de estratégias de guerra da Frente Farabundo Martí de Libertação Nacional e de instrutivos de guerrilha dos Estados Unidos (GUNDERSON, 2013; BARBOSA, 2015). Na metade de 1992, no marco das celebrações do Quinto Centenário de Invasão da América Latina, as comunidades indígenas chiapanecas decidem fazer sua própria celebração para denunciar a persistência de um colonialismo interno, de outras expressões da colonização, de despojo territorial e olvido histórico, reveladores do que representou a conquista para os povos indígenas, 500 anos antes. Com base nesse contexto políti$\mathrm{co}$, o Subcomandante Insurgente Marcos explica que o conteúdo da guerra anunciada pelo EZLN e os povos indígenas constituiu o prenúncio de um debate político mais amplo, para além da realização de uma revolução política, como as realizadas anteriormente:

La idea de un mundo más justo, todo lo que era el socialismo a grandes rasgos, pero digerido, enriquecido con elementos humanitarios, éticos, morales, más que propiamente indígenas. De pronto, la revolución se transforma en algo esencialmente moral. Ético. Más que el reparto de la riqueza o la expropiación de los medios de producción, la revolución comienza a ser la posibilidad de que el ser humano tenga un espacio de dignidad. La dignidad empieza a ser una palabra muy fuerte. No es un aporte nuestro, no es un aporte del elemento urbano, esto lo aportan las comunidades. De tal forma que la revolución sea el garante de que la dignidad se cumpla, se respete. (LE BOT, 1997, p. 61 -62). 
O ideário político de Mariátegui relacionado à conformação da consciência revolucionária indígena e de sua própria concepção do socialismo se materializa com o surgimento do EZLN e o levantamento armado em 1994, um processo histórico-político que, em palavras do Comandante Insurgente David, é resultado de:

Una larga historia de dolor y sufrimiento, pero también una larga lucha de resistencia y rebeldía. Hoy ha llegado la hora de romper los muros y las cadenas de injusticia. Ha llegado la hora de los pueblos indios. Los sin voz y los sin rostro tendrán por fin el rostro y la palabra que resonará en todos los rincones de la tierra [...] significa la construcción de una nueva sociedad basada en la justicia, en la igualdad y en el respeto a los indígenas con toda su diversidad de lenguas y culturas; una sociedad donde como indígenas no seamos ya humillados, marginados ni excluidos. Donde ya no tengamos que levantarnos en armas para ser escuchados y ser tomados en cuenta como pueblos. (EZLN, 2001, p. 04).

É válido destacar três elementos centrais que estruturam a identidade do EZLN: 1) uma matriz cultural e simbólica própria da cosmovisão e língua maia; 2) a organicidade herdada da tradição da luta política indígena-camponesa chiapaneca; e 3) o vínculo identitário com o território, não só como espaço de luta pela terra e pela reforma agrária, mas também como espaço de construção de relações sociais, culturais e políticas tecidas pela resistência, a rebeldia e locus legítimo de defesa de um ethos político com raízes ancoradas na cultura e organização política maia (BARBOSA, 2015; 2016).

Ao analisarmos os antecedentes do Zapatismo, observamos que sua complexidade dificulta defini-lo, unicamente, como um movimento social indígena ou um movimento de guerrilha armada. Se o considerarmos um fenômeno sócio-político, abarca elementos de ordem cultural, social e política da tradição da resistência camponesa-indígena mexicana, das lutas revolucionárias latino -americanas e caribenhas, com um embasamento teórico de corte marxista-leninista-maoísta-guevarista, e detentor de uma análise interpretativa permeada pela dimensão epistêmica da cosmovisão 
indígena (BARBOSA, 2013; 2015). Esta variedade de elementos constituintes confere ao Zapatismo uma riqueza histórico-cultural e política que lhes adjudica particularidades na concepção do processo revolucionário e na proposição de um projeto político emancipatório para os povos indígenas e, em particular, para a nação mexicana.

Inicialmente, o EZLN reivindicou, no plano político e jurídico, o reconhecimento dos direitos coletivos dos povos indígenas, pauta política aprimorada à demanda pela livre determinação e autonomia em seus territórios. Nos primeiros documentos emitidos, o EZLN (1994, p. 180) exigia: "a regiones, comunidades indígenas y municípios autogobernarse con autonomía política, económica y cultural", portanto, exigia uma dimensão territorial de autonomia. Além disso, também era requerida no âmbito político: "un nuevo pacto federal que acabe con el centralismo y permita la autonomía de comunidades indígenas y municípios" (EZLN, 1994, p. 261). Os Acordos de San Andrés sobre Direitos e Cultura Indígena ${ }^{17}$ figuram entre os episódios de maior incidência na trajetória política zapatista, uma vez que propiciou a abertura ao diálogo com o governo, com o intuito de modificar a Constituição Mexicana e outorgar direitos aos povos indígenas do México, em especial, o direito à autonomia (AUBRY, 2003). O documento resultante da mesa 1 apresenta a ampliação conceitual e política da autonomia, como sendo:

Los acuerdos de cambios constitucionales y de leyes a nivel nacional abren un espacio de participación indígena. Con estos acuerdos, el movimiento indígena nacional e independiente tiene un parteaguas que les permite avanzar en sus luchas por sus derechos y demandas. (EZLN, 1997, p. 143).

E acrescentam:

17 Firmado em 16 de fevereiro de 1996. Nessa ocasião foram convocadas organizações e intelectuais para participar de 05 mesas de discussão: 1. Direitos e Culturas Indígenas; 2. Democracia e Justiça; 3. Bem-Estar e Desenvolvimento; 4. Conciliação em Chiapas e 5. Direitos da Mulher. Entretanto, somente a primeira mesa foi discutida antes do encerramento dos diálogos. 
No basta que las comunidades indígenas se asocien en municipios, y éstos lo hagan para coordinar sus acciones. Se necesitan instancias autónomas que, sin ser exclusivamente indígenas, formen parte de la estructura del Estado y rompan con el centralismo. (EZLN, 1997, p. $151-152)$.

Nessa primeira etapa política, os zapatistas propunham uma reforma das estruturas do Estado, seja no marco legal e jurídico, seja no plano da participação democrática ou na incorporação de instâncias autônomas, não necessariamente indígenas, e que mediassem o enlace entre a autonomia no âmbito dos municípios rebeldes e o Estado. Portanto, não se propunha uma separação das instituições políticas oficiais, mas sim uma ampliação do espaço público institucional a uma efetiva participação política dos povos indígenas.

Entretanto, pese a pressão política do EZLN e da sociedade civil mexicana, o governo não cumpriu o negociado nos Acordos de San Andrés, culminando na retirada do EZLN das mesas de negociação e uma nova etapa na construção do projeto autonômico. Esta segunda etapa se consolida com a conformação dos Municípios Rebeldes Autônomos Zapatistas (MAREZ), um processo em que o território zapatista passa da condição de "rebelde" à de "rebelde autônomo". Há a explícita cisão com qualquer tentativa de diálogo com o Estado e a negação de sua dimensão institucional (BARBOSA, 2016).

Em 2003, são criados os "caracóis"18 e as Juntas de Bom Governo (JBG) ${ }^{19}$ e se consolida o projeto autonômico zapatista, com a organização interna dos MAREZ nas seguintes áreas: saúde autônoma, agroecologia (com uma reforma agrária a partir das

18 São os centros regionais administrativos e logísticos, responsáveis pela coordenação das atividades internas e externas no conjunto dos MAREZ. Em total são cinco "caracóis", a saber: Oventik, Morelia, La Garrucha, Roberto Barrios e La Realidad.

19 Constituem o coração administrativo do caracol. Estão conformadas por um ou dois delegados(as) dos conselhos autônomos dos MAREZ que são eleitos pela assembleia, principal instância participativa das bases de apoio zapatista. As atividades dos(as) delegados(as) são semanais e a cada sete dias se substitui o grupo, o que garante a rotatividade e gestão coletiva das responsabilidades, com base ao princípio da comunalidade. 
terras recuperadas), justiça autônoma, cooperativas (de produção, comercialização - nacional e internacional - e transporte) e a educação autônoma, esta denominada Sistema Educativo Rebelde Autônomo Zapatista de Libertação Nacional (SERAZ-LN). ${ }^{20}$ Todas estas instâncias são parte do Governo Civil Autônomo. O Comitê Clandestino Revolucionário Indígena - Comandância Geral (CCRICG) figura como instância formativa para a base civil zapatista. Fora dos seus territórios, os zapatistas estabeleceram alianças estratégicas com o Congresso Nacional Indígena (CNI), instância de articulação de todos os movimentos indígenas mexicanos, e com a Sexta nacional e internacional, ${ }_{1}^{21}$ para forjar um movimento político nacional, pacífico, sem vínculo institucional com o Estado e os partidos políticos.

Para os zapatistas, só é possível consolidar a autonomia como projeto político se houver a ruptura com todo o legado simbólico-ideológico da dominação de mais de 500 anos, o que implica assumir o "princípio da autonomia" como base da emancipação dos povos indígenas. A defesa da autonomia como princípio e projeto político reabre um debate histórico e teórico-político muito próprio à tradição do pensamento crítico marxista, o qual visa interpretar, em chave analítica, a autonomia em dois planos: como reafirmação do sujeito histórico-político e como característica do processo em si mesmo, isto é, do horizonte emancipatório de construção do socialismo.

Madonesi (2011) apresenta duas grandes abordagens do conceito de "autonomia" à luz da teoria crítica marxista: as perspectivas de Marx, Rosa Luxemburgo e Pannekoek, passando por Gramsci, Negri e Castoriadis, ademais das contraposições analíticas, como as desenvolvidas por Katsiaficas e Holloway. No centro dessa reflexão, se demonstra como o conceito de autonomia se

20 Para aprofundar a análise acerca do zapatismo, ver: Baronnet et. al. (2011), Barbosa $(2015 ; 2016)$ e Brancaleone (2015).

21 Na Sexta Declaração da Selva Lacandona, o EZLN desenvolve sua crítica à disputa hegemônica pela via institucional partidária, ao mesmo tempo em que convoca a sociedade civil mexicana para construir outra concepção de democracia por fora da via institucional. É lançada a chamada "Outra Campanha". 
erige no diálogo entre espontaneísmo e consciência. Além disso, enfatiza sua centralidade e indissociabilidade, ao lado de outras duas categorias - "subalternidade" e "antagonismo" - para interpretar os processos de subjetivação política próprios dos projetos que almejam a emancipação.

Em 2007, no marco do II Encontro dos Povos Zapatistas com os Povos do Mundo, os zapatistas realizam um importante balanço acerca dos resultados políticos do projeto autonômico, com destaque para a análise, em perspectiva marxista, da tomada dos meios de produção como princípio da emancipação humana. Nas palavras do então Tenente Coronel Insurgente Moisés: ${ }^{22}$

La tierra donde están ahora los compañeros es propiedad de ellos y ellas, la recuperamos. Descubrimos que para ir destruyendo a los capitalistas, es hacernos dueños de donde trabajamos, porque así funciona el capitalismo. Trabajas en fincas, en fábricas y la ganancia no es para el pueblo trabajador. En nuestra práctica la estamos descubriendo más el modo de cómo atacar el sistema capitalista. Como ustedes la verán en estos días de este segundo encuentro de los pueblos Zapatistas con los pueblos del mundo. Tendrán mucho que contarles las experiencias de los compañeros y compañeras, porque ahora están en sus manos su medio de producción, LA TIERRA. Es la base fundamental de la vida de ellos y ellas, también se entiende que el capitalismo es la base de ellos para explotar, en los medios de producción. Los compañeros y compañeras de los pueblos Zapatistas, cuando tomaron de sus manos ese medio de producción o sea la tierra, empezaron a trabajarla de manera comunal, local, regional, municipal, o sea en colectivos, sociedades, cooperativas. Esto se ha logrado, gracias a la recuperación, la toma de las tierras, sin eso, no estaríamos como estamos ahora. Esta clara para nosotros las y los Zapatistas, que a la hora que pasó a sernos dueños de esas tierras, como nuestro medio de producción, fue y es la base principal, para atacar el capitalismo, aunque nos hace muchas cosas por falte de hacer. Pero nuestro caminar ya sabemos por dónde ir. Todo esto nos dimos

22 Hoje Subcomandante Insurgente Moisés. 
cuenta a la hora que las quitamos las tierras de los mal llamados patrones, los terratenientes $o$ latifundistas. Los corrimos, con nuestra lucha del 1 de Enero del 94, la historia que ya ustedes ya conocen. (EZLN, 2007, [s.p.]) ${ }^{23}$

Importa dizer que os zapatistas se assumem como um movimento anticapitalista e antissistêmico, conforme se observa nas palavras do Tenente Coronel Insurgente Moisés: ${ }^{24}$

Creemos y que está claro, que para ser anticapitalista, es quitar los medios de producción, tierras y fábricas y pasar de las manos del pueblo trabajador, que sea propiedad del pueblo trabajador, acabar los explotadores, los patrones, el capitalista. Con la lucha y la práctica, en el trabajo del campo, de los compañeros y compañeras de los pueblos Zapatistas está a la vista de cómo debe ser anticapitalistas. Tomar, quitar, recuperar los medios de producción y a organizarse para las decisiones y a gobernarse con ella, sino hacemos esto reinara el neoliberalismo en México y en el mundo. Pensamos y creemos, que uniéndonos con los trabajadores del campo y la ciudad y organizándonos bajo una idea, de que el pueblo es quien manda y tomar de la mano todos los medios de producción esa es la salida que nos queda, ante este capitalismo salvaje que hoy reina. Esta es una de las características de nuestra organización del EZLN y una de las cosas más importantes de la Sexta Declaración de la Selva Lacandona, que es la guía de nuestro paso en La Otra Campaña y en la Zezta Internacional: el anticapitalismo. (EZLN, 2007, [s.p.]).

A partir de 2012, os zapatistas abrem um momento importante de diálogo com a sociedade civil mexicana e internacional, com a realização de dois eventos políticos: os dois níveis da "Escolinha Zapatista - A liberdade segundo os zapatistas" e o Seminário

23 Essa citação se refere a uma fala do Tenente Coronel Insurgente Moisés, em mesa redonda do seminário CIDECI, realizado em Sán Cristóbal de las Casas, em 19 de julho de 2007. Por estar disponível na internet, o referido texto não é paginado, o que indicamos pela notação [s.p.]. O mesmo ocorrerá nas demais citações da mesma fonte.

24 Cf. nota de rodapé 23. 
Internacional "O Pensamento Crítico Frente à Hidra Capitalista". ${ }^{25}$ A Escolinha Zapatista permitiu à sociedade civil mexicana e internacional conhecer, no âmbito das comunidades zapatistas, as conquistas, avanços, limites e desafios da trajetória do projeto autonômico nos MAREZ. No seminário internacional, os zapatistas problematizaram as dimensões do capitalismo na transição de séculos, com o intuito de elucidar, na perspectiva da economia política, as diferentes etapas de desenvolvimento do sistema capitalista e seus impactos nos territórios indígenas e camponeses. A alusão à mitologia grega da Hidra de Lerna em referência ao capitalismo evoca os desafios postos ao conjunto das lutas articuladas no campo latino-americano no enfrentamento de um modelo econômico que se manifesta cada vez mais enraizado com o capital transnacional e uma estrutura jurídico-legal que institucionaliza e legitima o processo de expropriação territorial e do neo-extrativismo na América Latina. Daí o reconhecimento de que o Estado funciona como instância de legitimação do aparato legal-jurídico e militar que garanta os mecanismos de reprodução do capital.

Um argumento central do seminário (EZLN, 2015) consistiu na reafirmação de que a genealogia da hidra capitalista assenta suas bases em contextos de guerra. Em outras palavras, historicamente o capitalismo tem mantido sua hegemonia ideológica e político-econômica graças a um estado de guerra permanente, seja nos contextos nacionais, impondo violentamente os novos padrões de acumulação do capital, a propósito das concessões às mineradoras e do sucessivo deslocamento, desaparições e assassinatos provocados nos territórios indígenas; ou ainda na geopolítica internacional, das constantes guerras impulsadas pela política imperialista dos países que compõem o G-20, sobretudo no Oriente Médio.

Se uma das condições de perpetuação do capitalismo é o contexto de guerras, no horizonte revolucionário zapatista, a luta política deve assumir por premissa ser antissistêmica e anticapitalista. Com o título alusivo à clássica obra de Lênin - O que fazer? - os zapatistas (EZLN, 2015) postulam os caminhos para a

25 Realizados em 2013 e 2015, respectivamente. 
superação do capitalismo como sistema-mundo. Na interpretação do atual estágio de desenvolvimento do capitalismo e de seu enraizamento político no Estado moderno, os zapatistas estabelecem uma crítica ferrenha às concepções vanguardistas da tomada do poder, sobretudo aquela baseada na democracia burguesa eleitoral, defensora de uma representatividade do povo pela via do voto. Sobre esta segunda crítica, os zapatistas consideram que o que hoje se reconhece pelo nome de "partido", em nada se relaciona à concepção original de Lênin. Justamente o contrário, na atual conjuntura política, os partidos se tornaram uma instância esvaziada de uma direção política popular, tornando-se espaços de articulação dos interesses de classe do capital transnacional e das forças políticas que buscam conformar uma estrutura de poder e um Estado que viabilize, no âmbito legal e jurídico, as plenas condições para a acumulação capitalista. Com relação ao posicionamento ante a via eleitoral, afirmam:

[...] nuestra idea no es promover el voto. Tampoco es para promover la abstención o el voto en blanco. [...] Sólo para que quede bien claro y no se dejen ustedes se engañar de que decimos lo que no decimos. Nosotros entendemos que hay quienes que sí, lo van a poder cambiar el sistema con votar las elecciones. [...] Está bien, nosotros no decimos que no, pero tampoco que sí [...] lo que nosotr@s decimos es que hay que organizarse y tomar en nuestras manos el quién es gobierno y obligarlo a que obedezca al pueblo. (EZLN, 2015, p. 342; 346-347).

Ainda durante o Seminário Internacional O Pensamento Crítico frente à Hidra Capitalista, os zapatistas alertam sobre a existência de um grande equívoco, comum à esquerda progressista, em confundir a posição de governo com a tomada do poder. Assim, asseveram que: "tal vez conviene que estudien un poco y aprendan que ser gobierno no es tener el Poder" (EZLN, 2015, p. 348). E afirmam categóricamente que: "las soluciones las hace el pueblo, no los líderes, no los partidistas" (EZLN, 2015, p. 343). A questão da (não) tomada do poder foi um debate fértil nos anos da Revolução Soviética, encontrando na voz e na pluma de Rosa Luxemburgo questionamentos nodais ante os próprios rumos do processo 
revolucionário. Reformar ou revolucionar? Esta foi a inquietude pulsante nas reflexões políticas de Luxemburgo e que instigou escritos capilares para o processo de construção do socialismo no século XX.

Rosa Luxemburgo não reconhecia a tomada do poder como uma etapa fundamental da revolução. Ponderava que a essência da sociedade socialista consistia em que: "a grande massa trabalhadora deixa de ser uma massa governada, para viver ela mesma a vida política e econômica na sua totalidade e para determiná-la por uma autodeterminação consciente e livre" (LUXEMBURGO, 1991, p. 103). Portanto, para Luxemburgo (2015), o processo revolucionário não prescindia de uma vanguarda intelectual partidária que determinaria as estratégias e táticas a utilizar, posto que o processo de organização da classe trabalhadora deveria ser expressão e obra de sua consciência crítica, construída coletivamente no seio da própria experiência revolucionária. Portanto, concebia a emancipação no movimento dialético revolucionário e não na tomada do poder, uma vez que o socialismo deveria conduzir à autonomia, à ruptura com a tutela política do Estado.

Durante o V Congresso Nacional Indígena, ocorrido em outubro de 2016, os zapatistas propuseram ao CNI a conformação de um Conselho Indígena de Governo para as eleições presidenciais de 2018, no México. O anúncio zapatista de um possível caminho eleitoral reascendeu o debate da esquerda internacional, a qual celebrava que, "finalmente", os zapatistas cediam à perspectiva da tomada do poder como parte constitutiva da transição ao socialismo. Entretanto, a decisão do CNI era lançar uma candidatura independente, sem filiação partidária, de uma mulher indígena que seria considerada porta-voz do Conselho Indígena de Governo, conformado por representantes das organizações do CNI. Quando se deu a conhecer o conteúdo político da proposta, não tardaram as críticas de uma parte da esquerda internacional, sobretudo com relação à negação do EZLN e do CNI à vanguarda partidária como instância legítima de representação popular.

Em maio de 2017, o CNI anuncia o nome de María de Jesús Patrício Martínez, conhecida como "Marichuy" como a candidata do Conselho Indígena de Governo. Importante salientar que todo 
este processo se deu a partir de consultas em assembleias realizadas nas comunidades indígenas de todo o país. De igual maneira, as principais decisões foram anunciadas em território zapatista, o que confere o reconhecimento, por parte do $\mathrm{CNI}$, do papel político desempenhado pelo Zapatismo enquanto referente de luta política emancipatória. No presente momento, o EZLN e o CNI convocam a sociedade civil a impulsar a Rede de Apoio ao Conselho Indígena de Governo, com o intuito de construir o debate da questão indígena e da nova etapa da luta histórica em perspectiva popular. Outro objetivo é a arrecadação de um milhão de assinaturas para o registro da candidatura independente de Marichuy.

\section{DO LEGADO E DAS RUPTURAS: REFLEXÕES FINAIS}

O centenário da Revolução Soviética suscita uma revisão do percurso da luta socialista internacional, sobretudo em apontar a atualidade do socialismo como projeto político para a emancipação humana. Para Marx (1986), cada período histórico elabora suas próprias leis, com uma certeza: cabe à classe trabalhadora destruir o Estado burguês, assertiva que também se fazia presente em Lênin no momento da Revolução.

A dura crítica aos zapatistas, que em realidade recai sobre Holloway (2003), é demasiado estreita na compreensão do que implica consolidar a autonomia como arma legítima da classe trabalhadora do campo e da cidade na luta permanente contra o capital (CLEAVER, 1985). Ao realizar a denúncia histórica da falácia da democracia burguesa, os zapatistas demonstram o risco eminente na assunção de uma posição de governo, para a quebra de um sincronismo entre a preparação da correlação de forças para um processo revolucionário e a construção de uma hegemonia verdadeiramente popular. Portanto, revigoram as possibilidades da luta emancipatória por meio da revolução, algo que deve ser valorizado ante um momento político em que o capitalismo celebra "a morte do socialismo como projeto político". Ao insurgir em armas, o fazem inspirados no legado revolucionário soviético e latino-americano, com a clara demonstração de que a revolução é obra dos oprimidos do mundo, condição que não se limita ao trabalhador urbano. 
E aqui nos parece oportuno retomar um escrito de Che Guevara (1969), no qual problematiza o horizonte político da teoria revolucionária e dos sujeitos da revolução. Nas suas palavras, "a Revolução pode ser feita se interpretada corretamente a realidade histórica e se utilizadas corretamente as forças que nela intervêm, ainda que não se conheça a teoria" (GUEVARA, 1969, p. 10). Na perspectiva de uma "teoria revolucionária", acrescenta:

Deve enfatizar que seus atores principais não eram exatamente teóricos, mas também não eram ignorantes dos grandes fenômenos sociais e dos enunciados das leis que os regem. Isso fez com que, sobre a base de alguns conhecimentos teóricos e profundo conhecimento da realidade, se pudesse ir criando uma teoria revolucionária. [...] Os avanços na ciência social e política, como em outros campos, pertencem a um longo processo histórico cujos elos se encadeiam, se somam, se aglutinam e se aperfeiçoam constantemente. [...] Por isso, quando banhados em suor camponês, com um horizonte de montanhas e nuvens, sob o sol ardente da Ilha, entraram em Havana o chefe rebelde e seu cortejo, uma nova "escadaria do jardim de inverno subia a história com os pés do povo". (GUEVARA, 1969, p. 13).

O fato é que o século XXI nos dá exemplos concretos de como os movimentos sociais latino-americanos e caribenhos erigem caminhos revolucionários assim como uma "teoria revolucionária" - não apenas uma "teoria da revolução". As lutas desencadeadas ao longo da nossa história recente têm revisitado permanentemente o legado da teoria crítica para pensar, amiúde, a compreensão das particularidades regionais, identificar a natureza sociocultural e política de seus sujeitos e, a partir de um posicionamento histórico-político, apropriar-se e reinventar sua própria concepção da luta política e do processo revolucionário, conforme preconizavam Luxemburgo e Mariátegui. Nessa direção, no percurso de construção do pensamento crítico, na esteira das contradições do capital nos umbrais do século XXI, afirma o Subcomandante Insurgente Marcos: 
[...] habría que volver a pensar a Marx, Lenin, Gramsci, Mao, Trotsky, Che Guevara y otros revolucionarios porque ninguna propuesta responsable de cambio radical en nuestra época puede ignorar el análisis y las enseñanzas de estos revolucionarios y de los movimientos que encabezaron. (EZLN, 1996, p. 51).

No processo da luta revolucionária, os zapatistas conclamam a organização popular. Em suas palavras:

Por eso, nosotras, nosotros, las y los Zapatistas, no nos cansamos de decir, organícense, organicémonos, cada quien en su lugar, luchemos por organizarse, trabajemos por organizarse, pensemos por empezar a organizar y encontrémonos por unir nuestras organizaciones por un Mundo donde los pueblos mandan y gobierno obedece. (EZLN, 2015, p. 348).

Ao mesmo tempo, enfatizam a centralidade do pensamento crítico, que se nutre das diferentes fontes das lutas históricas:

[...] pensamos que hay que tener buen pensamiento para organizarnos. O sea que se necesita la teoría, el pensamiento crítico. Con el pensamiento crítico lo analizamos sus modos del enemigo, de quien nos oprime [...] con el pensamiento crítico vamos viendo cómo es nuestro camino, cómo son nuestros pasos. Por eso estamos llamando toda la Sexta para que hagan reuniones de pensamiento, de análisis, de teoría, de cómo ven su mundo, su lucha, su historia. Los llamamos a que hagan sus propios semilleros y nos compartan lo que ahí siembren. (EZLN, 2015, p. 348 - 349).

Por último, destacamos o escrito do Subcomandante Insurgente Galeano intitulado Kamegusha: abril también es mañana, ${ }^{26}$ no qual se reconhece a Revolução Cubana como um referente central na luta internacional pelo socialismo e a emancipação dos povos. Reconhecer Cuba é reconhecer o legado dos demais processos revolucionários, entre eles, a alma mater que representa a Revolução Soviética de 1917.

26 Sugerimos a leitura do texto que se encontra disponível em: <http:// enlacezapatista.ezln.org.mx/2017/04/12/kagemusha-abril-tambien-esmanana/>. Acesso em: 20 out. 2017. 


\section{REFERÊNCIAS}

AUBRY, A. Los acuerdos de San Andrés. Chiapas: Centro Estatal de Lenguas, Arte y Literatura Indígena, 2003.

BAMBIRRA, V. El capitalismo dependiente latinoamericano. México: Siglo XXI, 1980.

BARBOSA, L. P. Educação rebelde e autônoma na práxis revolucionária zapatista. In: REBUÁ, E.; SILVA, P. (orgs.). Educação e filosofia da práxis: reflexões de fim de século. Rio de Janeiro: Letra Capital. 2016. p. 48 - 79.

Educación, resistencia y movimientos sociales: la praxis educativo-política de los Sin Tierra y de los Zapatistas. México: LIBRUNAM, 2015.

Educación, movimientos sociales y Estado en América Latina: estudio analítico de las experiencias de resistencia contrahegemónica en Brasil y México. 2013. 366f. Tesis (Doctorado en Estudios Latinoamericanos) - Programa de Posgrado en Estudios Latinoamericanos, Universidad Nacional Autónoma de México, Ciudad de México, 2013. Disponible en: $<$ http://132.248.9.195/ptd2013/noviembre/0706520/0706520.pdf>. Acceso en: 20 out. 2017.

BARONNET, B. et al. Luchas "muy otras": zapatismo y autonomía en las comunidades indígenas de Chiapas. México: CIESAS-UNACH-UAM, 2011.

BELL, J. et al. Documentos de la Revolución Cubana - 1959. La Habana: Editorial de Ciencias Sociales, 2006.

BEDAÑA, A. Sandino: patria y libertad. Manágua: Ediciones Anama, 2016.

BLACK, G. Triumph of the People: The Sandinista Revolution in Nicaragua. London: Zed Press, 1981.

BRANCALEONE, C. Teoria social, democracia e autonomia: uma interpretação da experiência de autogoverno zapatista. Rio de Janeiro: Travessias, 2015.

CASTELLANOS, R. Ofício de Tinieblas. México: Editorial Planeta, 2012.

Balún-Canán. 6. ed. México: Fondo de Cultura Económica, 2007.

CEDILlO-CEDILLO, A. El suspiro del silencio: de la reconstrucción de las Fuerzas de Liberación Nacional a la fundación del Ejército Zapatista de Liberación Nacional (1974-1983). 2010. 263f. Tesis (Maestría) - Programa de Posgrado en Estudios Latinoamericanos, Universidad Nacional Autónoma de México, Ciudad de México, 2010.

CLEAVER, H. Una lectura política del "El Capital". México: Fondo de Cultura Económica, 1985. 
CUSICANQUI, S. R. Oprimidos pero no vencidos. Bolívia: Hisbol, 1986. EZLN - Ejército Zapatista de Liberación Nacional. El pensamiento crítico frente a la hidra capitalista. San Cristóbal de las Casas: [s.n.], 2015.

Palabras del Teniente Coronel Insurgente Moisés. Mesa redonda en el CIDECI, Sán Cristóbal de las Casas, 19 jul. 2007. Disponible en: $<$ http://enlacezapatista.ezln.org.mx/2007/07/20/mesa-redonda-en-elcideci-san-cristobal-de-las-casas/>. Acceso en: 20 out. 2017.

La marcha del color de la tierra: comunicados, cartas y mensajes del Ejército Zapatista de Liberación Nacional. México: Rizoma, 2001.

Documentos y comunicados. Tomo II. México: ERA, 1997.

Documentos y comunicados. Tomo I. México: ERA, 1994.

GILLY, A. La revolución interrumpida. México: ERA, 2007.

GONZÁLEZ-CASANOVA, P. De la sociología del poder a la sociología de la emancipación: pensar América Latina en el siglo XXI. Buenos Aires: CLACSO, 2015.

(coord.). Historia política de los campesinos latinoamericanos: Brasil, Chile, Argentina, Uruguay. v. 4. México: Siglo XXI Editores, 1985a.

Historia política de los campesinos latino-americanos: Colombia, Venezuela, Ecuador, Perú, Bolivia, Paraguay. v. 3. México: Siglo XXI Editores, 1985b.

Historia política de los campesinos latino-americanos: Guatemala, Honduras, El Salvador, Nicaragua, Costa Rica, Panamá. v. 2. México: Siglo XXI Editores, 1985c.

Historia política de los campesinos latino-americanos: México, Cuba, Haití, República Dominicana, Puerto Rico. v. 1. México: Siglo XXI Editores, 1984.

GRAMSCI, A. Os intelectuais e a organização da cultura. São Paulo: Círculo do Livro, 1981.

GUEVARA, E. Notas para o estudo da ideologia da Revolução Cubana. Revista Verde Olivo, Cuba, p. 10-13, 12 out. 1969. Disponível em: <http:// clcnce.blogspot.com.br/2017/02/notas-para-o-estudo-da-ideologia-da. html>. Acesso em: 20 out. 2017.

GUNDERSON, C. The Provocative Cocktail: Intellectual Origins of the Zapatista Uprising, 1960-1994. 2013. 606f. Thesis (PhD of Philosophy) - Graduate Faculty in Sociology, City University of New York, New York, 2013. Available at: <https://pqdtopen.proquest.com/doc/1430904296. html?FMT=AI $>$. Access on: oct. 20, 2017. 
HERZOG, J. S. Breve historia de la Revolución Mexicana. México: Fondo de Cultura Económica, 1972.

HOLLOWAY, J. Mudar o mundo sem tomar o poder: o significado da revolução hoje. São Paulo: Boitempo, 2003.

KATZ, F. Pancho Villa. México: ERA, 1998.

LE BOT, Y. El sueño zapatista. [S.l.: s.n.], 1997. [Escrito com a cooperação do Subcomandante Insurgente Marcos]. Disponível em: $<\mathrm{http}$ ///enriquedussel.com/txt/Textos_200_Obras/PyF_revolucionarios_ marxistas/Sueno_zapatista-Yvon_Le_Bot.pdf>. Acesso em: 20 out. 2017.

LEYVA-SOLLANO, X. Identidad étnica, política y religión en la región del conflicto: Chiapas Hoy - análisis antropológico y social. México: INAH, 1994.

LUXEMBURGO, R. Reforma ou Revolução?. São Paulo: Expressão Popular, 2015.

A Revolução Russa. Petrópolis: Vozes, 1991.

MADONESI, M. El concepto de autonomía en el marxismo contemporáneo. In: ADAMOVSKY, E. et al. Pensar las autonomías: alternativas de emancipación al capital y al Estado. México: Sísifo Ediciones; Bajo Tierra, 2011.

MARIÁTEGUI, J. C. El problema de la raza en América Latina. In:

Obras. Tomo II. La Habana: Casa de las Américas, 1982. p 296 - 299.

Siete ensayos de interpretación de la realidad peruana. México: ERA, 1928.

MARINI, R. M. Dialética da dependência. Petrópolis: Vozes, 2000.

MARTÍ I PUIG, S. Nicaragua (1979 - 1990): la revolución enredada. León: Libros de la Catarata y Cooperación, 2012.

MARX, K. O dezoito Brumário e cartas a Kugelmann. Rio de Janeiro: Paz e Terra, 1986.

OLIVER, L. Transformaciones recientes del Estado integral en América Latina: críticas y aproximaciones desde la sociología política de Antonio Gramsci. México: UNAM; Ediciones La Biblioteca, 2016.

SVAMPA, M. Cambio de época: movimientos sociales y poder político. Buenos Aires: Siglo Veintiuno, 2009.

TSÉ-TUNG, M. Sobre a prática e a contradição. Rio de Janeiro: Zahar, 2008. 
WARMAN, A. Y venimos a contradecir. México: La Casa Chata, 1976.

ZEA, L. Mariátegui y el hombre llamado indígena. In: WEINBERG, L. I.; BAO, R. M. Mariátegui: entre la memoria y el futuro de América Latina. México: UNAM; Cuaderno del Cuaderno, 2000. p. 15 - 31. 